\title{
Early Detection of Precursors of Cervical Cancer with Cervical Cytology and Visual Inspection of Cervix with Acetic Acid
}

\author{
Dhaubhadel P, ' Vaidya A, ' Choudhary P' \\ 'Maternity Hospital, Thapathali, Kathmandu, Nepal
}

\section{ABSTRACT}

A hospital-based, prospective study was done in 350 women of 20-50 years to compare VIA with Pap smear for early detection of cervical dysplasia at Maternity Hospital, Thapathali, from May 2004 to December 2004. Pap smear was taken from each woman followed by VIA. Women with positive VIA and/or positive Pap smear were referred for colposcopy-directed cervical biopsy. The variables studied were age group, presenting complaint, age of marriage, parity, smoking habit and appearance of cervix.

The incidence of positive VIA and Pap smear was 2.86 and 0.57 respectively. Pelvic pain was the most common presenting complaint. The majority of the women were married before 20 years of age. All women with either positive VIA and/or Pap smear were of parity two or above. There was no significant association between smoking and positive VIA $(\mathrm{P}=0.699)$ or Pap smear $(\mathrm{P}=0.397)$. Approximately $36.57 \%$ of the women screened had abnormal looking cervix. There were two women with high grade intraepithelial lesion (HSIL) and both were VIA positive and this was statistically significant (Fischer exact $\mathrm{P}=0.0007$ ). Of the ten VIA positive women, on histopathological examination six showed chronic cervicitis, one acute cervicitis, one showed cervical intraepithelial neoplasia (CIN) II, one had normal finding and one was lost to follow up.

VIA as a screening test for cervical neoplasia did not miss any lesion detected by Pap smear and confirmed by cervical biopsy.

Key words: cervical neoplasia, pap smear, visual inspection

\section{INTRODUCTION}

Cervical cancer has a major impact on the lives of women worldwide. It is the second most common cancer among women in the world. ${ }^{1}$ It constitutes 15 $51 \%$ of all female cancers. ${ }^{2}$ According to the latest global estimate, 493,000 new cases of cervical cancer occur each year, of which, 409,400 (83\%) occur in women of developing countries while only 84,400 cases occur in that of developed countries. ${ }^{3}$ Cervical cancer has a long premalignant phase. If it is detected and treated in this phase, advanced disease can be prevented. Unfortunately, more than $80 \%$ of cases are diagnosed at an advanced clinical stage when five-year survival is less than $40 \% .^{2}$ Cervical cancer results from the uncontrolled growth of abnormal cells in the cervix. The primary cause of carcinoma cervix is Human Papilloma Virus (HPV), the most common sexually transmitted infection worldwide.

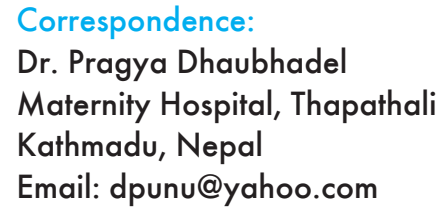


Dhaubhadel et al. Early Detection of Precursors of Cervical Cancer with Cervical Cytology and...

A good deal of attention is being paid to cervical cancer screening. The only screening technique currently recommended by WHO is the Papanicolaou (Pap) smear test. ${ }^{4}$ This is a cytological test that detects abnormal cervical cells. Regular testing with Pap smear started in the 1950s and has become the standard of care in most developed countries. Screening based on Pap smear at a minimum cost requires trained providers and a reliable cytological laboratory. It requires an effective referral mechanism and multiple follow-up visits for diagnosis and treatment of the disease. In developing countries, such a strategy has proven difficult to implement and sustain due to financial and technical constrains. On the other hand, cervical cancer continues to be a major problem in these countries. Thus, other methods of cervical cancer screening provision need to be investigated.

The current $\mathrm{WHO}$ recommendation is to evaluate visual inspection to identify early curable cervical cancer. ${ }^{5}$ Visual inspection of cervix with application of acetic acid (VIA) seems to be a more promising alternative to Pap smear for identifying women with precancerous lesion or cancer. VIA has a number of potential advantages over Pap smear as a screening test for cervical cancer. The costs associated with launching and sustaining VIAbased program is generally low; it is therefore possible to perform VIA in low-resource settings. The technique is simple and easy to learn, and little infrastructure is required. As the result of the procedure is available immediately, it is possible to provide or plan further management of a suspected precancerous lesion during the same visit.

\section{MATERIAL AND METHODS}

A hospital-based prospective and descriptive study conducted in Shree Panch Paropakar Indra Rajya Laxmi Devi Prasuti Griha Hospital, Thapathali, Kathmandu, Nepal. It was conducted from May, 2004 to December, 2004. During the study period, 2,108 women attended the Gynecology Out-Patient Department of which 350 women were enrolled in the study. Women of age group 20-50 years. who attended the Gynecology out patient department (OPD) were included and women with pregnancy, bleeding per vagina, who had undergone subtotal hysterectomy, diagnosed case of cervical cancer were excluded.

After taking informed verbal consent, the relevant history was taken and a brief general physical examination was done followed by per-speculum examination. Visual inspection of the exposed cervix was done. A Pap smear was collected with Ayre's spatula scraping all around the cervix including the entire transformation zone. Next, a cotton-tipped applicator soaked in freshly prepared $5 \%$ acetic acid $(5 \mathrm{ml}$ of acetic acid with $95 \mathrm{ml}$ of distilled water) was applied to the cervix all over the transformation zone and left in situ for one minute. The abnormal epithelium appeared white and this was taken as a VIA positive test. The result of VIA was noted diagrammatically in the proforma. This was followed by pelvic examination. All women with either a VIA positive test and/or a Pap positive smear were referred for colposcopy followed by biopsy. A pap smear report of high grade intraepithelial lesion (HSIL) and above was taken as a positive test result.

\section{RESULTS}

During the study period 2,180 women attended to the Gynecology OPD during the study period and 350 of them were enrolled. The percentage of women screened was $16.6 \%$. Of the women screened, VIA was positive in ten $(2.86 \%)$ among this two were PAP smear positive $(0.57 \%)$. Most of the women were in the $30-34$ years. age group $(26.29 \%)$ and a VIA positive result was the highest in this group $(5.43 \%)$ (Table 1$)$. All women $(n=10)$ with either a positive VIA and/or a positive Pap smear were of parity two or above (Table 2).

Pelvic pain was the most common presenting complaint $(56.86 \%)$ of the women screened. Six $(3.02 \%)$ of them had a positive VIA test and one $(0.5 \%)$ had a positive Pap smear. Abnormal per vaginal discharge was the second most common presenting complaint (27.43\%). Positive VIA and positive Pap smear was $2.08 \%$ and $1.04 \%$ respectively among these women (Table 3 ).

The majority of the women were married before 20 years of age $(80 \%)$. However, no significant association was seen between early age of marriage and positive VIA (Fischer exact $\mathrm{P}=0.118$ ) or Pap smear $\left(\chi^{2} \mathrm{P}=0.316\right)$ (Table 4).

The majority of women were non-smokers $(77.71 \%)$. There was no significant association between smoking and positive VIA $\left(\chi^{2} \mathrm{P}=0.699\right)$ or Pap smear (Fischer exact $P=0.397$ ) (Table 5).

Out of 350 women screened, 128 of them $(36.57 \%)$ had an abnormal looking cervix. Of the ten VIA positive women, six $(60 \%)$ had abnormal looking cervix while both $(n=2)$ women with positive Pap smear had similar findings.

The majority of the women had a normal Pap smear $(82.86 \%)$ of which $1.72 \%(n=5)$ showed a positive VIA. There were two women with a high-grade intraepithelial lesion (HSIL) and both were VIA positive, a statistically significant result (Fischer exact $\mathrm{P}=0.0007$ ) (Table 6).

Of the ten VIA positive women, nine had a biopsy from the cervix. On histopathological examination, six showed chronic cervicitis, one acute cervicitis, one 
Dhaubhadel et al. Early Detection of Precursors of Cervical Cancer with Cervical Cytology and...

Table 1. Screening Results in Relation to Age Distribution

\begin{tabular}{|c|c|c|c|c|c|c|c|c|}
\hline \multirow{2}{*}{$\begin{array}{c}\text { Age group in } \\
\text { years }\end{array}$} & \multirow{2}{*}{$\begin{array}{c}\text { Number of } \\
\text { cases }\end{array}$} & \multirow[t]{2}{*}{$\%$} & \multicolumn{3}{|c|}{ VIA Positive } & \multicolumn{3}{|c|}{ Pap Positive } \\
\hline & & & Total No. & $\%$ & $\begin{array}{c}\text { Chi square } \\
\text { p value }\end{array}$ & Total No. & $\%$ & $\begin{array}{c}\text { Chi square } \\
P \text { value }\end{array}$ \\
\hline $20-24$ & 50 & 14.29 & 0 & 0 & & 0 & 0 & \\
\hline $25-29$ & 78 & 22.29 & 2 & 2.56 & & 0 & 0 & \\
\hline $30-34$ & 92 & 26.29 & 5 & 5.43 & & 1 & 1.09 & \\
\hline $35-39$ & 51 & 14.57 & 2 & 3.92 & 0.422 & 0 & 0 & 0.589 \\
\hline $40-45$ & 46 & 13.14 & 1 & 2.17 & & 1 & 2.17 & \\
\hline $46-50$ & 33 & 9.42 & 0 & 0 & & 0 & 0 & \\
\hline Total & 350 & 100 & 10 & 2.86 & & $2 \dagger$ & 0.57 & \\
\hline
\end{tabular}

Table 2. Screening Results in Relation to Parity

\begin{tabular}{ccccccc}
\hline \multirow{2}{*}{ Parity } & Number of cases & $\%$ & Total No. & $\%$ & Total No. & $\%$ \\
\hline 0 & 6 & 1.71 & 0 & 0 & 0 & 0 \\
1 & 52 & 14.86 & 0 & 0 & 0 & 0 \\
2 & 114 & 32.57 & 4 & 3.50 & 1 (HSIL) & 0.88 \\
3 & 82 & 23.43 & 2 & 2.44 & 0 & 0 \\
4 & 42 & 12 & 1 & 2.38 & 0 & 0 \\
5 & 27 & 7.71 & 1 & 3.70 & 1 (HSIL) & 3.70 \\
$\geq 6$ & 27 & 7.71 & 2 & 7.40 & 0 & 0 \\
Total & 350 & 100 & $10 *$ & 2.86 & 2 & 0.57 \\
\hline
\end{tabular}

${ }^{*} \chi^{2} \mathrm{P}=0.670 \quad \mathrm{t} \chi^{2} \mathrm{P}=0.415$

Table 3. Screening Results in Relation to Chief Presenting Complaint

\begin{tabular}{lcccccc}
\hline Chief complaint & \multicolumn{2}{c}{ Number of cases } & $\%$ & Total No. & $\%$ & \multicolumn{2}{c}{ Pap Positive } \\
\hline Pelvic pain & 199 & 56.86 & 6 & 3.02 & 1 (HSIL) & 0.50 \\
Abnormal discharge P/V & 96 & 27.43 & 2 & 2.08 & 1 (HSIL) & 1.04 \\
Urinary symptoms & 16 & 4.57 & 1 & 6.25 & 0 & 0 \\
Intermenstrual bleeding & 8 & 2.29 & 0 & 0 & 0 & 0 \\
Postcoital bleeding & 3 & 0.86 & 0 & 0 & 0 & 0 \\
Post menopausal bleeding & 1 & 0.28 & 0 & 0 & 0 & 0 \\
Others & 27 & 7.71 & 1 & 3.70 & 0 & 0 \\
Total & 350 & 100 & 10 & 2.86 & 2 & 0.57 \\
\hline
\end{tabular}


Dhaubhadel et al. Early Detection of Precursors of Cervical Cancer with Cervical Cytology and...

Table 4. Screening Results in Relation to Age at Marriage

\begin{tabular}{lcccccccc}
\hline $\begin{array}{l}\text { Age at } \\
\text { marriage }\end{array}$ & $\begin{array}{l}\text { Number } \\
\text { of cases }\end{array}$ & $\%$ & Total No. & $\%$ & $\begin{array}{c}\text { Fischer exact } \\
\mathbf{p} \text { value }\end{array}$ & Total No. & $\%$ & $\mathbf{X}^{2} \mathbf{P}$ value \\
\hline$<20$ Yrs & 280 & 80 & 6 & 2.14 & & 1 (HSIL) & 0.36 \\
$\geq 20$ Yrs & 70 & 20 & 4 & 5.71 & 0.118 & 1 (HSIL) & 1.43 & 0.316 \\
Total & 350 & 100 & 10 & 2.86 & & 2 & 0.58 \\
\hline
\end{tabular}

Table 5. Screening Results in Relation to Smoking

\begin{tabular}{ccccccccc}
\hline $\begin{array}{c}\text { No. of } \\
\text { cigarettes }\end{array}$ & $\begin{array}{c}\text { Number of } \\
\text { cases }\end{array}$ & $\%$ & Total No. & $\%$ & $\begin{array}{c}\text { VIA Positive } \\
\text { p value }\end{array}$ & Total No. & $\%$ & $\begin{array}{c}\text { Pischer exact } \\
\text { P value }\end{array}$ \\
\hline No & 272 & 77.71 & 7 & 2.57 & & 1 (HSIL) & 0.37 \\
Yes & 78 & 22.29 & 3 & 3.85 & 0.699 & 1 (HSIL) & 1.28 & 0.397 \\
Total & 350 & 100 & 10 & 2.86 & & 2 & 0.57 & \\
\hline
\end{tabular}

Table 6. Correlation of Cytopathology with VIA

\begin{tabular}{lcccc}
\multicolumn{1}{c}{ Pap report } & Number of cases & $\%$ & Number of cases & $\%$ \\
\hline Normal smear & 290 & 82.86 & 5 & 1.72 \\
Inflammation & 58 & 16.57 & 3 & 5.17 \\
ASCUS & 0 & 0 & 0 & 0 \\
LSIL & 0 & 0 & 0 & 0 \\
HSIL & 2 & 0.57 & $2 *$ & 100 \\
Invasive & 0 & 0 & 0 & 0 \\
Total & 350 & 100 & 10 & 2.86 \\
\hline
\end{tabular}

${ }^{*}$ Fischer exact $\mathrm{P}$ value $=0.0007$

showed cervical intraepithelial neoplasia (CIN) II and one had normal finding. Cervical biopsy could not be taken from the remaining one as she did not come for follow-up.

\section{DICUSSION}

Despite the high prevalence of cervical cancer in developing countries, few effective screening programs are available. The reasons for this include lack of trained personnel, laboratory facilities and equipments, the high cost of services and difficulty in following up patients. The aim of this study was to investigate the value of visual inspection of cervix after application of Acetic Acid as an alternative to cytological screening.
Women of age group ranging from 20-50 years with a mean age of 31.1 years were included in this study, which is comparable to studies done by Megevand et al as 31 years and by Cronje et al as 34.4 years. ${ }^{6-7}$ The maximum number of the screened population was in the age group 35-39 years, similar to the study done by Basu. ${ }^{8}$ Usually, screening programs of cervical cancer worldwide are targeted towards this age group. This was the reason for screening only this age group of women in this study, as most premalignant lesions are expected to occur in this age group.

In the present study, the most common clinical presentation $(56.86 \%)$ among screened women was pelvic pain $(n=199)$, followed by $(27.43 \%)$ abnormal 
Dhaubhadel et al. Early Detection of Precursors of Cervical Cancer with Cervical Cytology and...

discharge per vagina $(n=96)$. This is similar to the study done by Singh et al in which $81.4 \%$ of women had complaints of abdominal pain and discharge per vagina. ${ }^{9}$ Pain is the most distressing experience to human beings and pelvic pain is one of the most common reasons for gynecology consultation. This might be the reason for it to be the most common clinical presentation of the women in this study. The least common complaint was postmenopausal bleeding $(0.28 \%)$. This could be because the maximum age limit in this study was 50 years, which allowed very few post menopausal women to get enrolled in the study. Various other studies have offered screening regardless of the women's presenting complaints.

In this study, $22.29 \%$ of the women were smokers, which is higher than that reported by Denny et al as $5.3 \%$, Claeys et al as $7.5 \%$ and Cronje et al as 16\%.7,10,11 This disparity could be because the majority of the women in this study were from rural hilly areas where smoking is a common habit. The prevalence of positive VIA and Pap smear was more among the smokers, $3.85 \%$ and $1.28 \%$ respectively, compared to $2.57 \%$ and $0.37 \%$ among non-smokers but this result was not statistically significant. Smoking as a risk factor of premalignant lesions of the cervix cannot be commented in this study due to the small study population.

On speculum examination, $36.57 \%$ of the women had an abnormal looking cervix, which is much higher than that reported by Sankaranarayanan et al as $7.2 \%$ and Singh et al as $11.4 \%$. They had screened a much larger population of 3,000 and 44,970 women respectively. ${ }^{9,12}$ The high result in the present study could be due to the hospital based study as well as to the study targeted to symptomatic women attending gynecology OPD. There were 128 women with an abnormal looking cervix of which six had a positive VIA test and two had a positive Pap test. Two women were both VIA and Pap test positive and both belonged to the abnormal looking cervix group. Twenty percent of the women had ectopy $(n=70)$ followed by $6.28 \%$ ectropion $(n=22), 4.57 \%$ cervicitis $(n=16), 3.43 \%$ cervical polyp $(n=12), 2 \%$ hypertrophied cervix $(n=7)$ and $0.29 \%$, leukoplakia $(n=1)$.

On Cytology, two women had HSIL $(0.57 \%)$, which is very low compared to the result by Lynette Denny et al which was $17 \% .{ }^{13}$ There were no women with lesion higher than HSIL. None of the women with a negative VIA test had a positive Pap smear.

In this study, $82.86 \%$ of the women had a normal Pap smear of which five were VIA positive (1.72\%). Biopsy of these five cases revealed chronic cervicitis in three cases, acute cervicitis in one case and squamous metaplasia in one case. Fifty eight women had inflammatory smear (16.57\%) of which three were VIA positive, and histology of all three cases showed features of chronic cervicitis. Similar studies done have not commented on normal and inflammatory Pap smears.

Out of 350 women enrolled in the study, 10 women $(2.86 \%)$ had a positive result on VIA and/or Pap smear. These women were referred for colposcopy but only nine underwent colposcopy-directed biopsy $(2.57 \%)$ while woman was lost to follow up. The screening test positive rate in this study is much lower than that reported by Denny et al. ${ }^{10}$ In their study, $44 \%$ of the women screened had a positive result on the screening test whereas Claeys et al reported $32.7 \%$. The reason behind this disparity could be due to the small number of sample taken in this study. ${ }^{11}$ The percentage of women with positive VIA were 2.86 whereas it extends from $3.13 \%$ in a study by Megevand et al to $41 \%$ by Ngelangel et al. ${ }^{6-14}$

Even though, the sensitivity and specificity of acetowhite staining to detect HPV infections has not been properly studied in gynaecology various study have shown that he application of acetic acid is not a useful adjunct to biopsy selection and then histological diagnosis in the larynx and in the oral cavity malignancy. ${ }^{15,16}$

VIA showed the superiority over the PAP smear to detected cervical carcinoma and its precursors on histology. The histology of these eight cases revealed chronic cervicitis in six women, acute cervicitis among one of them and squamous metaplasia in one. Acetowhiting of cervical epithelium following application of acetic acid is seen not only in cervical carcinoma and its precursors but also in HPV infection, squamous metaplasia, healing/regenerating epithelium and inflammation. This could be the reason for the high false positive VIA.

Women with negative tests on both VIA and cytology did not undergo colposcopy and cervical biopsy to confirm the negative result. Therefore, the accuracy of the tests for screening of cervical cancer could not be calculated in this study.

\section{CONCLUSION}

Cervical cancer is a major health problem of women of developing countries. In our study VIA as a screening test did not miss any lesion detected by Pap smear and confirmed by cervical biopsy. The limitation of this study was the inability to comment on the sensitivity and the specificity of the two screening tests. The major drawback of VIA is its high false positive rate which may increase the number of referrals and often unnecessary treatment. 
Dhaubhadel et al. Early Detection of Precursors of Cervical Cancer with Cervical Cytology and...

Visual inspection of cervix with acetic acid is a very simple, cheap and easy screening test for cervical cancer. It is a good alternative to Pap smear for cervical cancer screening in places where facility for cytological test is not available. The fact that VIA is the only screening test at present which gives immediate result makes it the most suitable "see and treat" test for prevention of cervical cancer.

\section{ACKNOWLEDGMENT}

I would like to thank Mr. Ganesh Acharya, Maternity Hospital, Thapathali, for his support in various form to carry out this study.

\section{REFERENCES}

1. Shafi MI. Premalignant and malignant disease of the cervix. Dewhurt's textbook of obstetrics and gynecology for post graduates. 6th ed. London: Blackwell Science; 1999. p. 57281.

2. Shatri SS, Dinshaw K, Amin G, Goswami S, Patil S, Chinoy $\mathrm{R}$, et al. Concurrent evaluation of visual, cytological and HPV testing as screening methods for the early detection of cervical neoplasia in Mumbai, India. Bulletin of World Health Organization 2005; 83(30):186-94.

3. Preventing cervical cancer worldwide. Alliance for Cervical Cancer Prevention. Population Reference Bureau 2004.

4. Department of Reproductive Health and Research. World Health Organization (Switzerland). Organization of screening programmes. Progress in Reproductive Health Research 2004:65;3.

5. Kitchener HC, Symonds P. Detection of cervical intraepithelial neoplasia in developing countries. Lancet. 1999 Mar 13;353(9156):856-7.

6. Megevand E, Denny L, Dehaeck K, Soeters R, Bloch B. Acetic acid visualization of the cervix: an alternative to cytologic screening. Obstet Gynecol. 1996 Sep;88(3):383-6.

7. Cronjé HS, Cooreman BF, Beyer E, Bam RH, Middlecote BD, Divall PD. Screening for cervical neoplasia in a developing country utilizing cytology, cervicography and the acetic acid test. Int J Gynaecol Obstet 2001 Feb;72(2):151-7.

8. Basu PS, Sankaranarayanan R, Mandal R, Roy C, Das P, Choudhury $\mathrm{D}$, et al. Visual inspection with acetic acid and cytology in the early detection of cervical neoplasia in Kolkata, India. Int J Gynecol Cancer 2003 Sep-Oct;13(5):626-32.
9. Singh V, Sehgal A, Luthra UK. Screening for cervical cancer by direct inspection. BMJ 1992 Feb 29;304(6826):534-5.

10. Denny L, Kuhn L, Pollack A, Wright TC Jr. Direct visual inspection for cervical cancer screening: an analysis of factors influencing test performance. Cancer. 2002 Mar 15;94(6):1699707.

11. Claeys P, De Vuyst H, Gonzalez C, Garcia A, Bello RE, Temmerman M. Performance of the acetic acid test when used in field conditions as a screening test for cervical cancer. Trop Med Int Health 2003 Aug;8(8):704-9.

12. Sankaranarayanan $R$, Wesley $R$, Somanathan $T$, Dhakad N, Shyamalakumary B, Amma NS, et al. Visual inspection of the uterine cervix after the application of acetic acid in the detection of cervical carcinoma and its precursors. Cancer. 1998 Nov 15;83(10):2150-6.

13. Denny L, Kuhn L, Pollack A, Wainwright H, Wright TC Jr. Evaluation of alternative methods of cervical cancer screening for resource-poor settings. Cancer 2000 Aug 15;89(4):826-33.

14. Ngelangel CA, Limson GM, Cordero CP, Abelardo AD, Avila JM, Festin MR, et al. Acetic-acid guided visual inspection vs. cytology-based screening for cervical cancer in the Philippines. Int J Gynaecol Obstet. 2003 Nov;83(2):141-50.

15. Soh KB, Westmore GA, Banerjee AR. Acetowhite staining in the detection of laryngeal disease. Clin Otolaryngol Allied Sci. 1996 Jun;21(3):252-5.

16. Kellokoski J, Syrjänen S, Kataja V, Yliskoski M, Syrjänen K. Acetowhite staining and its significance in diagnosis of oral mucosal lesions in women with genital HPV infections. J Oral Pathol Med 1990 Jul;19(6):278-83. 